\title{
Evidence that continuous normothermic blood cardioplegia offers better myocardial protection than intermittent hypothermic cardioplegia
}

The Cardiothoracic Centre, Liverpool E D Grech

R Steyn

R D Page

B M Fabri

D R Ramsdale

A Rashid

Department of Clinical Chemistry, Royal Liverpool and Broadgreen

University Hospitals, Liverpool

$M$ Baines

Department of

Statistics, Withington

Hospital, Manchester

E B Faragher

Correspondence to:

Dr E D Grech, Departmen of Cardiology, Glenfield

Hospital, Groby Road,

Leicester LE 390 .

Accepted for publication 26 April 1995

Ever D Grech, Malcolm Baines, Richard Steyn, E Brian Faragher, Richard D Page, Brain M Fabri, David R Ramsdale, Abbas Rashid

\section{Abstract}

Objectives-To compare transmyocardial ischaemia and oxidative stress, as well as non-infarction myocardial injury, in patients randomised to intermittent hypothermic cardioplegia or continuous normothermic blood-potassium cardioplegia.

Design-Prospective randomised trial. Setting-Tertiary cardiac referral centre. Methods-24 patients undergoing elective coronary artery bypass surgery were randomised to hypothermic (13 patients, mean (SEM) age $59.5(2.6)$ years) or normothermic (11 patients, mean (SEM) age $59.7(3.3)$ years) cardioplegia. Transmyocardial oxidative stress and ischaemia were assessed by the difference in plasma concentrations of oxidised glutathione and lactate respectively, from samples taken simultaneously from the coronary sinus and aortic root. Blood samples were taken just before cross clamp application and at intervals up to $15 \mathrm{~min}$ after cross clamp release. Noninfarction myocardial injury was assessed by measurement of creatine kinase $M B$ isoenzyme activity from peripheral venous blood taken 2 and $18 \mathrm{~h}$ after surgery.

Results-Intermittent hypothermic cardioplegia resulted in a significant increase in transmyocardial ischaemia ( $P$ $<0.001)$ and oxidative stress $(P<0.001)$. Evidence of significantly increased myocyte damage was also present $(P<$ $0 \cdot 01)$. No significant corresponding changes were present with normothermic cardioplegia.

Conclusions-Normothermic blood cardioplegia seems to avoid significant changes in myocardial ischaemic status and consequent oxidative stress. This study provides direct evidence that normothermic cardioplegia offers enhanced myocardial protection compared with that of hypothermic cardioplegia. Certain subsets of patients may derive more benefit from normothermic cardioplegia, although it is unclear whether this would be the case for all patients.

\section{(Br Heart f 1995;74:517-521)}

Keywords: continuous normothermic cardioplegia; intermittent hypothermic cardioplegia; myocardial protection; ischaemia and oxidative stress
In 1989 a new concept in myocardial protection was initiated as an alternative to the standard use of hypothermia. ${ }^{1}$ This technique involved continuous, normothermic bloodpotassium perfusion during the cross clamp period, which aims to provide an uninterrupted supply of oxygenated blood to the myocardium. Not only has continuous normothermic cardioplegia been found to be safe and effective, but it has also been proposed that the method provides a superior means of myocardial protection over intermittent cold blood cardioplegia. ${ }^{2-7}$ No prospective study, however, has been carried out to show benefit in terms of myocardial metabolism and free radical activity. ${ }^{8}$

The aims of this study were to examine transmyocardial oxidative stress and ischaemia, using plasma oxidised glutathione and lactate concentrations, in patients undergoing elective coronary artery bypass surgery by two different methods of myocardial protection: (a) anterograde induction followed by intermittent retrograde hypothermic cardioplegia (group A); and (b) anterograde induction followed by continuous, retrograde normothermic blood-potassium cardioplegia (group B). In addition, differences in noninfarction myocardial injury were assessed by measurement of serum creatine kinase MB isoenzyme concentrations from peripheral venous blood taken 2 and $18 \mathrm{~h}$ after surgery.

\section{Patients and methods}

PATIENTS

In this prospective study comprising 24 patients, 13 were randomised to group $A$ and 11 to group B. Randomisation was carried out according to the patient's hospital number, and all patients underwent elective coronary artery graft surgery only. The study was approved by the hospital ethical committee.

\section{OPERATIVE TECHNIQUES}

All patients underwent cardiopulmonary bypass using an ascending aortic cannula for arterial return and a two stage venous cannula inserted into the right atrium. A Cobe CML membrane oxygenator (Cobe Laboratories, Quedgeley), in line filter, and crystalloid prime were utilised. In addition to the cannulations for bypass, a coronary sinus perfusion cannula was introduced through a separate purse string suture in the right atrium and manually guided into the coronary sinus.

In group $\mathrm{A}$, cardiopulmonary bypass was carried out at moderate systemic 
hypothermia, with a nasopharyngeal temperature of $28^{\circ} \mathrm{C}$. Cardiac arrest was induced after aortic cross clamping with an anterograde infusion of blood cardioplegic solution $(600 \mathrm{ml})$ into the aortic root (composition: potassium chloride $20 \mathrm{mmol} / 1$ for initial dose, $10 \mathrm{mmol} / \mathrm{l}$ for repeat doses; calcium $0.6 \mathrm{mmol} / 1$; glucose $225 \mathrm{mmol} / \mathrm{l}$; osmolality 320-360 mmol $/ \mathrm{kg} ;$ pH 7.8-8.0 (THAM); haematocrit $20-25 \%$; temperature $4-6^{\circ} \mathrm{C}$ ). A further $400 \mathrm{ml}$ was infused retrogradely through a coronary sinus cannula. Flow through the coronary sinus was adjusted to maintain a pressure of $<60 \mathrm{~mm} \mathrm{Hg}$ at the tip of the catheter. This resulted in flow rates of about $250 \mathrm{ml} / \mathrm{min}$. Myocardial cooling was further enhanced by continuous pericardial irrigation with saline at $4^{\circ} \mathrm{C}$. The aortic root was vented throughout the period of aortic cross clamping.

The distal graft anastomoses were then carried out, with sequential retrograde infusion of cardioplegic solution ( $200 \mathrm{ml})$ after completion of each graft or after $20 \mathrm{~min}$, whichever occurred first. A "hot shot" of normothermic $\left(37^{\circ} \mathrm{C}\right)$ cardioplegic solution was infused retrogradely after completion of the last distal anastomosis and before removal of the aortic cross clamp. Proximal anastomoses were carried out during systemic rewarming and the patient weaned off bypass at $37^{\circ} \mathrm{C}$.

In group $\mathrm{B}$, cardiopulmonary bypass was carried out at normothermia, keeping the nasopharyngeal temperature between 35 and $37^{\circ} \mathrm{C}$ throughout by active heating of the perfusate. The composition and method of delivery of warm blood cardioplegic solution have been described previously. ${ }^{9}$ In summary, oxygenated blood was taken from a side branch of the arterial line of the oxygenator, to which was added a variable concentration of potassium chloride via a syringe driver. No further additives were infused. Cardiac arrest was induced after aortic cross clamping by antero-

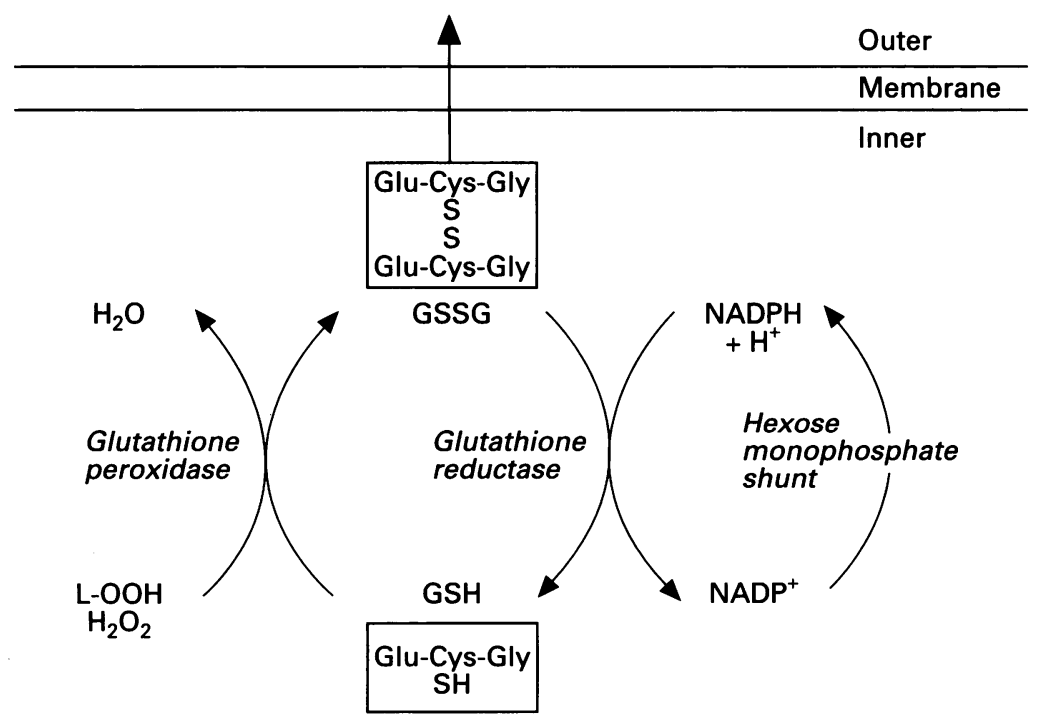

Figure 1 Cellular formation and removal of oxidised glutathione (GSSG) after free radical interaction with reduced glutathione (GSH). grade infusion of the cardioplegic solution into the aortic root, at a rate of $200 \mathrm{ml} / \mathrm{min}$. Delivery was switched to a retrograde route when cardiac arrest had been achieved. Pressure at the tip of this cannula was measured continuously, and the flow adjusted to keep the pressure $<60 \mathrm{~mm} \mathrm{Hg}$. This resulted in flow rates of $200-250 \mathrm{ml} / \mathrm{min}$, which were not interrupted throughout aortic clamping. Such a flow rate falls within the acceptable range. ${ }^{10}$

Potassium concentration of the cardioplegic solution was varied to ensure continued electromechanical arrest. The potassium concentration was $20 \mathrm{mmol} / 1$ during induction of arrest, but was reduced to $8-10 \mathrm{mmol} / 1$ for maintenance.

ASSAYS

Plasma oxidised glutathione (GSSG) was measured by the method of Abdalla et al ${ }^{11}$ modified as described here. Fresh whole blood $(1 \mathrm{ml})$ was added to a tube containing $N$-ethylmaleimide solution $(1 \mathrm{ml}) . N$-ethylmaleimide forms a complex with reduced glutathione (GSH) and prevents further formation of GSSG. The plasma was removed into a polypropylene tube after centrifugation at $2000 \mathrm{~g}$ for $8 \mathrm{~min}$ and stored in liquid nitrogen until analysed. Thawed plasma $(500 \mu \mathrm{l})$ was passed through a $\mathrm{C} 18$ solid phase extraction cartridge unendcapped (Technicol, Stockport, UK), which had been previously washed with methanol $(1 \mathrm{ml})$ and deionised water $(2 \mathrm{ml})$, and the cartridge rinsed with phosphate imidazole buffer $(1 \mathrm{ml})$. The combined eluate was stored in chilled water and analysed without delay. A reagent blank $(0.01$ $\mathrm{mol} / \mathrm{l}$ hydrochloric acid), an internal standard (250 nmol/1 GSSG (Sigma, Poole, Dorset) in $0.01 \mathrm{~mol} / 1$ hydrochloric acid, and a test plasma to which the equivalent of $250 \mathrm{nmol} / 1$ GSSG had been added (recovery plasma) were treated with $N$-ethylmaleimide and passed through the $\mathrm{C} 18$ cartridge as described above. Enzymatic analysis was carried out by mixing the eluate $(700 \mu \mathrm{l})$ with a solution $(300 \mu \mathrm{l})$ containing dithionitrobenzoic acid $(0.87 \mathrm{mmol} / 1$ in a buffer of potassium phosphate $(100 \mathrm{mmol} / \mathrm{l})$, disodium EDTA $(17.5$ $\mathrm{mmol} / \mathrm{l}) \mathrm{pH} 7 \cdot 5$, and glutathione reductase (type IV; 5 units/ml) (Sigma) and $300 \mu \mathrm{l}$ of NADPH $(0.8 \mathrm{mmol} / \mathrm{l})$ (Sigma). The reaction was monitored kinetically at $412 \mathrm{~mm}$ for 10 min. Plasma GSSG was calculated by reference to the blank corrected internal standard, after correcting for recovery indicated by the recovery plasma. A final correction for the blood haematocrit was made.

Plasma lactate was measured on a protein free sample obtained by mixing fresh whole blood $(500 \mu \mathrm{l})$ with perchloric acid $(0.6$ $\mathrm{mol} / \mathrm{l})(1 \mathrm{ml})$. After mixing and centrifugation $(2000 \mathrm{~g}$ for $10 \mathrm{~min})$ the supernatant was stored in liquid nitrogen. The sample was thawed for analysis and measured using an enzymatic method utilising lactate dehydrogenase (Sigma). Serum creatine kinase MB isoenzyme was measured by an immunoinhibition method (Sigma). 
Figure 2 Study protocol. Circles indicate sample collection.

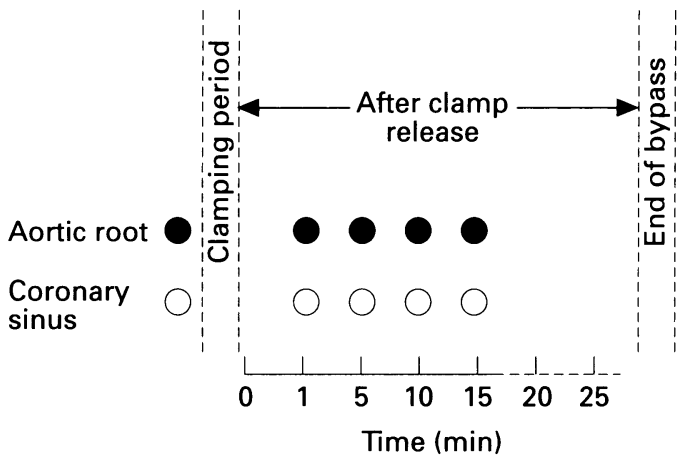

Figure 3

Transmyocardial oxidised glutathione (GSSG) gradients in groups $A$ and $B$. (Data are mean (SEM)). ${ }^{\star \star * P}<0.001$.

Figure 4

Transmyocardial lactate gradients in groups $A$ and $B$. (Data are mean (SEM)). $\star \star \star P<0.001$.

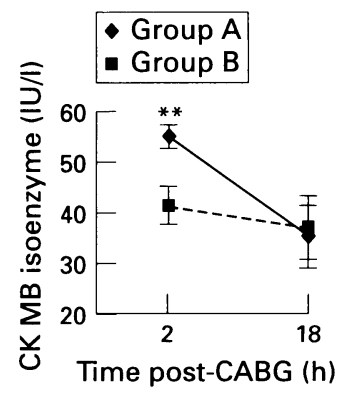

Figure 5 Serum creatine kinase $M B(C K M B)$ isoenzyme activity in groups $A$ and $B$ at 2 and $18 \mathrm{~h}$ after coronary artery $18 \mathrm{~h}$ after coronary artery
bypass surgery $(C A B G)$. bypass surgery (CABG).
(Data are mean (SEM). $\star \star P<0.01$.

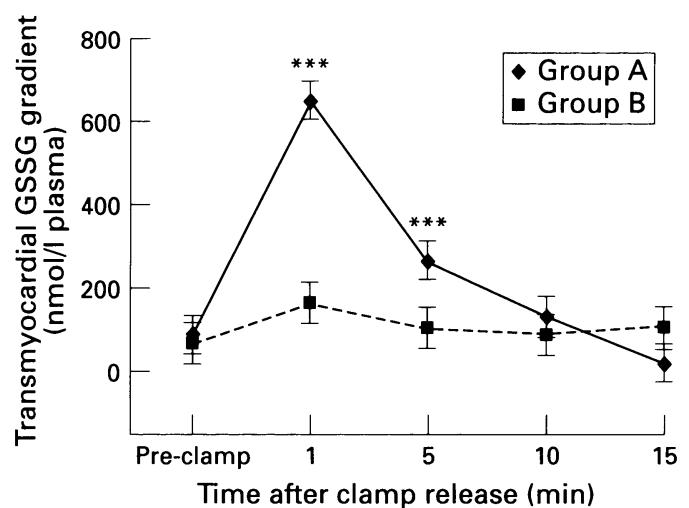
5,10 , and $15 \mathrm{~min}$ after cross clamp release. Transmyocardial oxidative stress and ischaemia were assessed by the difference in plasma concentrations of GSSG and lactate respectively.

\section{STATISTICAL ANALYSIS}

Data were analysed by fitting a series of mathematical models by the method of maximum likelihood as described by Aitken ${ }^{13}$; this is equivalent to an analysis of variance, but permits the use of patients with incomplete data. using the Tukey multiple comparison test. Separate analyses were carried out on transmyocardial plasma GSSG, lactate, and serum creatine kinase $\mathrm{MB}$ isoenzyme differences. Best statistical estimates of the group means and their standard errors were obtained from the models fitted. Computations were performed using the GLIM 3.77 computer statistical package (NAG, Oxford). Although statistical significance was set at conventional levels, differences close to significance at the $5 \%$ level are also discussed.

\section{Results}

The table gives the baseline clinical characteristics of the study patients. Thirteen patients (mean (SEM) age 59.5 (2.6) years) were randomised to group A and 11 (mean (SEM) age $59.7(3.3)$ years) to group B. There were no significant differences between the two groups. None of the study patients showed evidence of perioperative myocardial infarction on the basis of serial electrocardiographs or increased activity of serum creatine kinase MB isoenzyme (> $130 \mathrm{IU} / \mathrm{l}$ ).

Figure 3 shows the transmyocardial GSSG gradients in groups $\mathrm{A}$ and $\mathrm{B}$ before and at timed intervals after cross clamp release. There was no significant change in transmyocardial stress after cross clamp removal in group B. In group A, however, there was a sharp increase within $1 \mathrm{~min}$ of cross clamp release, followed by a decline reaching baseline within $10 \mathrm{~min}$. The changes over time were highly significant at $1(P<0.001)$ and 5 $\min (P<0.01)$ relative to the pre-clamp baseline concentration. Significant differences between groups were apparent only at 1 and 5 $\min (\mathrm{P}<0.001)$ only.

Transmyocardial lactate gradients in group B showed no significant change after cross clamp removal (fig 4). In group A there was a sharp increase within $1 \mathrm{~min}$ of cross clamp release, followed by a decline reaching baseline within $10 \mathrm{~min}$. The changes over time were highly significant at $1(P<0.001)$ and 5 min $(P<0.01)$ relative to the pre-clamp baseline concentration. Significant differences between the two groups were apparent at 1 $\min (P<0.001)$. Significance was not reached at $5 \mathrm{~min}$, although this was very close (significant at the $10 \%$ level).

Significant differences in the mean serum creatine kinase isoenzyme activity between the two groups were present at $2(P<0.01)$ but not $18 \mathrm{~h}$ after coronary artery bypass surgery (fig 5). A significant decrease was observed Significant findings were evaluated in detail
Patient characteristics

\begin{tabular}{lcc}
\hline & Group $A$ & Group B \\
\hline No of patients & 13 & 11 \\
Sex ratio (M:F) & $10: 3$ & $9: 2$ \\
Mean (SEM) age (years) & $59 \cdot 5(2 \cdot 6)$ & $59 \cdot 7(3 \cdot 3)$ \\
$\begin{array}{l}\text { Mean (SEM) } \\
\text { bypass time (min) }\end{array}$ & $122 \cdot 2(9 \cdot 3)$ & $127 \cdot 5(11 \cdot 0)$ \\
$\begin{array}{l}\text { Mean (SEM) } \\
\text { cross clamp time (min) }\end{array}$ & $63 \cdot 1(3 \cdot 6)$ & $66 \cdot 3(7 \cdot 0)$ \\
$\begin{array}{l}\text { Mean (SEM) conduits grafted } \\
\text { (SE) }\end{array}$ & $3 \cdot 8(0 \cdot 2)$ & $3 \cdot 4(0 \cdot 3)$ \\
\hline
\end{tabular}


between 2 and $18 \mathrm{~h}$ in group $A(P<0.01)$; however, no significant change was present in group B.

\section{Discussion}

During open heart surgery, such as coronary artery bypass grafting, a period of aortic cross clamping and cardiac arrest is necessary to allow the procedure to be carried out. During this period, however, coronary arterial supply is interrupted resulting in global myocardial ischaemia. Reoxygenation when the cross clamp is released may result in oxidative stress and reperfusion injury. Rosenkranz and Buckberg ${ }^{14}$ have defined reperfusion injury as "those metabolic, functional and structural consequences of restoring coronary arterial flow... that can be avoided or reversed by modification of the conditions of reperfusion." This has been attributed to oxygen derived free radicals, ${ }^{15-17}$ which have been shown to be directly cytotoxic. ${ }^{18-20}$ Clinically recognisable components of reperfusion injury include reperfusion arrhythmias, myocardial stunning, and lethal myocyte injury. ${ }^{21}$ Hence, functional recovery after bypass surgery may be impaired, and studies in humans have demonstrated that free radical sequestrants may reduce reperfusion injury after bypass surgery. ${ }^{22-25}$ Patients subjected to longer periods of global ischaemia induced during the cross clamp period showed a greater degree of oxidative stress during reperfusion and a significant delay in the rate of functional recovery than those with shorter cross clamp periods. ${ }^{12}$

Hypothermia and cardioplegic solutions are commonly used in an attempt to reduce cardiac metabolism and oxygen consumption, thereby minimising the ischaemic insult and hence oxidative stress after cross clamp release. In 1983, Rosenkranz and Buckberg ${ }^{14}$ showed that functional recovery could be significantly improved if the arresting and reperfusing solution was modified. They concluded that prevention of reperfusion damage was possible as the surgeon was in control of the temperature and composition of the reperfusate blood. ${ }^{14}$ A new concept of myocardial protection was introduced in 1989 using continuous warm blood cardioplegia and is being adopted in an increasing number of cardiac surgical centres. ${ }^{1}$ Several reports have described its efficacy and safety in large series. $^{2-7}$ Concerns that it may result in increased neurological damage (TD Martin $e t$ al, 29th annual meeting of the Society of Thoracic Surgeons, San Antonio, Texas, 1993) or inadequate right ventricular protection have not been substantiated (TD Martin et al, 29th annual meeting of the Society of Thoracic Surgeons). ${ }^{62-29}$ It has been pointed out, however, that evidence of benefit in terms of myocardial metabolism and free radical activity is lacking. ${ }^{8}$ Therefore, this prospective randomised study has set out to directly examine differences between continuous, warm blood cardioplegia and the more standard use of intermittent hypothermic cardioplegia.
Previous coronary artery bypass surgery and surgical revascularisation studies have used indirect markers of free radical activity, such as plasma diene conjugates of 9,11octa-decadieneoic acid and malonaldehyde..$^{30} 31$ However, their relation to free radicals and their accuracy have been subject to controversy. ${ }^{32}{ }^{33}$ Moreover, systemic heparin, which is routinely administered during bypass surgery, increases diene conjugate formation. ${ }^{34}$ In light of the limitations and reservations imposed by the use of indirect biochemical markers we used GSSG, which reflects intracellular response to free radical generation and hence cellular oxidative stress.

Glutathione (GSH), a sulphydryl containing tripeptide, is an abundant intracellular molecule that has a vital role in the cellular protection against oxygen derived free radical species. It acts as a co-substrate for glutathione peroxidase, reducing hydrogen peroxide and other peroxides to produce GSSG. Because the cell tries to maintain as high a GSH/GSSG ratio as possible, any increase in GSSG produces an active efflux of this molecule across the cell membrane to the plasma ${ }^{35}$ (fig 1). Thus, the arteriovenous difference in plasma GSSG across the myocardium has been considered a sensitive indicator of myocardial oxidative stress. ${ }^{11}$ In a similar manner, the arteriovenous difference in plasma lactate, formed from pyruvate under anoxic conditions, ${ }^{36}$ may be considered an indicator of relative myocardial ischaemia.

Clear differences in transmyocardial ischaemia and oxidative stress between the two study groups were observed. A significant transmyocardial ischaemia was present for up to 5 min after cross clamp release in group A despite the use of hypothermia and cardioplegic solution. This was sufficient to cause a corresponding increase in transmyocardial oxidative stress over the same time period. In addition, evidence of increased myocyte damage, assessed by measurement of serum creatine kinase $M B$ isoenzyme, was seen. It is unclear whether this damage is caused by ischaemia induced by cross clamping or subsequent oxidative stress. Either way, normothermic cardioplegia seems to avoid significant changes in ischaemic status and hence averts ensuing oxidative stress.

No patients showed electrocardiographic or serological evidence of perioperative infarction. Such patients would have been excluded from the analysis as the resulting increase in serum creatine kinase MB isoenzyme concentration would have distorted assessment of non-infarction myocardial damage.

This study provides direct evidence of enhanced myocardial protection by normothermic over cold cardioplegia. Global ischaemic reperfusion is a potential threat to viable myocardium that may impair functional recovery after bypass surgery. Continuous normothermic cardioplegia is technically more difficult, however, because of increased blood around the operative field. ${ }^{6}$ It remains to be seen whether all patients would benefit significantly from this technique. 
Patients with established poor ventricular function or those who have already suffered a prolonged ischaemic insult (such as after acute infarction or abrupt coronary artery occlusion from interventional angioplasty) and who may not be able to tolerate further iatrogenic ischaemic myocardial injury may have more to gain from normothermic cardioplegia than those with well preserved ventricular function.

1 Lichtenstein SV, el Dalati H, Panos A, Slutsky AS. Long cross-clamp times with warm heart surgery. Lancet 1989;i: 1443 .

2 Lichtenstein SV, Fremes SE, Abel JG, Christakis GT, Salerno TA. Technical aspects of warm heart surgery. f Card Surg 1991;6:278-85.

3 Lichtenstein SV, Ashe KA, el Dalati H, Cusimano RJ, Panos A, Slutsky AS. Warm heart surgery. F Thorac Cardiovasc Surg 1991;101:269-74.

4 Loesser KE, Kukreja RC, Kazziha SY, Jesse RL, Hess ML. Oxidative damage to the myocardium: a fundamental mechanism of myocardial injury. Cardioscience mental mechanism

5 Salerno TA, Houck JP, Barrozo CA, et al. Retrograde continuous warm blood cardioplegia: a new concept in myocardial protection. Ann Thorac Surg 1991;51:245-7.

6 Rashid A, Fabri BM, Jackson M, et al. A prospective randomised study of continuous warm versus intermittent cold blood cardioplegia for coronary artery surgery: preliminary report. Eur $\mathcal{F}$ Cardiothorac Surg 1994;8:265-9.

7 The warm heart investigators. Randomised trial of normothermic versus hypothermic coronary bypass normothermic versus hypothermic

8 Warm heart surgery [editorial]. Lancet 1992;339:841-2.

9 Page RD, Sharpe DA, Bellamy CM, Rashid A, Fabri BM. Normothermic arrest with continuous hyperkalaemic blood: initial experience. Eur $\mathcal{f}$ Cardiothorac Surg 1992; 6:461-8.

10 Ikonomidis J, Yau T, Weisel R, et al. Optimal flow rates for retrograde warm cardioplegia. $\mathcal{F}$ Thorac Cardiovasc Surg 1994;107:510-9.

11 Abdalla EK, Caty MG, Guice KS, Hinshaw DB, Oldham KT. Arterial levels of oxidized glutathione (GSSG) reflect oxidant stress in vivo. 7 Surg Res 1990;48:291-6.

12 Ferrari $R$, Alfieri $O$, Curello $S$, et al. Occurrence of oxidative stress during reperfusion of the human heart. Circulation 1990;81:201-11.

13 Aitken MA. The analysis of unbalanced cross-classifications. F Roy Statist Soc 1978;141:195-223.

14 Rosenkranz ER, Buckberg GD. Myocardial protection during surgical coronary reperfusion. $\mathcal{\exists} \mathrm{Am}$ Coll Cardiol 1983;1:1235-46.

15 Zweier JL, Flaherty JT, Weisfeldt ML. Direct measurement of free radical generation following reperfusion of ischemic myocardium. Proc Natl Acad Sci USA 1987. 84:1404-7.

16 Ytrehus $\mathrm{K}$, Myklebust $\mathrm{R}$, Olsen $\mathrm{R}$, Mjos OD. Ultrastructural changes induced in the isolated rat heart by enzymatically genera

17 Guarnieri C, Flamigni F, Caldarera CM. Role of oxygen in the cellular damage induced by re-oxygenation of hypoxic heart. $\mathcal{A}$ Mol Cell Cardiol 1980;12:797-808.
18 Bernier M, Hearse DJ, Manning AS. Reperfusion-induced arrhythmias and oxygen-derived free radicals. Studies with "anti-free radical" interventions and a free radicalgenerating system in the isolated perfused rat heart. Circ Res 1986;58:331-40.

19 Bolli R, Jeroudi MO, Patel BS, et al. Direct evidence that oxygen-derived free radicals contribute to postischemic oxygen-derived free radicals contribute to postischemic myocardial dysfunction in the

20 Werns SW, Shea MJ, Driscoll EM, et al. The independent effects of oxygen radical scavengers on canine infarct size. Reduction by superoxide dismutase but not catalase. Circ Res 1985;56:895-8.

21 Hearse DJ. Reperfusion-induced injury: a possible role for oxidant stress and its manipulation. Cardiovasc Drugs Ther 1991;5(2):225-35.

22 Ferreira R, Burgos M, Milei J, et al. Effect of supplementing cardioplegic solution with deferoxamine on reperfused cardioplegic solution with deferoxamine on reperfused 708-14.

23 Sunamori $M$, Tanaka $H$, Maruyama $T$, Sultan I, Sakamoto T, Suzuki A. Clinical experience of coenzyme Q10 to enhance intraoperative myocardial protection in coronary artery revascularization. Cardiovasc Drugs Ther $1991 ; 5(2): 297-300$

24 Ferrari R, Curello S, Boffa GM, et al. Oxygen free radicalmediated heart injury in animal models and during bypass surgery in humans. Effects of alpha-tocopherol. Ann N Y Acad Sci 1989;570:237-53.

25 Johnson WD, Kayser KL, Brenowitz JB, Saedi SF. A randomised controlled trial of allopurinol in coronary bypass surgery. Am Heart $\mathcal{f}$ 1991;121:20-4.

26 Caldarone C, Krukenkamp I, Misare B, Levitsky S. Perfusion deficits with retrograde warm blood cardioplegia. Ann Thorac Surg 1994;57:403-6.

27 Carrier M, Gregoire J, Khalil A, Thai P, Latour J, Pelletier L. Myocardial distribution of retrograde cardioplegic solution assessed by myocardial thallium 201 uptake. $\mathcal{F}$ Thorac Cardiovasc Surg 1994;108:1115-8.

28 Gates R, Laks H, Drinkwater D, et al. Gross and microvascular distribution of retrograde cardioplegia in explanted human hearts. Ann Thorac Surg 1993;56:410-17.

29 Lichtenstein S, Abel J, Slutssky A. Warm retrograde cardioplegia: protection of the right ventricle in mitral valve operations. F Thorac Cardiovasc Surg 1992;104:374-80.

30 Davies SW, Underwood SM, Wickens DG, Feneck RO, Dormandy TL, Walesby RK. Systemic pattern of free radical generation during coronary bypass surgery. Br Heart $₹$ 1990;64:236-40.

31 Rabl H, Khoschsorur G, Colombo T, Tatzber F, Esterbauer $\mathrm{H}$. Human plasma lipid peroxide levels show a strong transient increase after successful revascularization operations. Free Radic Biol Med 1992;13:281-8.

32 Halliwell B, Chirico S. Lipid peroxidation: its mechanism, measurement, and significance. Am $¥$ Clin Nutr 1993; measurement

33 Thompson S, Smith MT. Measurement of the diene conjugated form of linoleic acid in plasma by high performance liquid chromatography: a questionable noninvasive assay of free radical activity? Chem Biol Interact 1985;55:357-66.

34 Wickens DG, Griffin JF, Maher ER, Curtis JR, Dormandy TL. The effect of systemic heparinisation and haemodialysis on plasma octadeca-9,11-dienoic acid (9,11-LA'). Free Radic Res Commun 1987;3:99-106.

35 Sies H, Akerboom TPM. Glutathione disulphide (GSSG) efflux from cells and tissues. Methods Enzymol 1984; 105:445-51.

36 Alberti KGMM, Nattrass M. Lactic acidosis. Lancet 1994; ii: $25-9$. 